\title{
Formation of glacier tables caused by differential ice melting
}

\author{
Marceau Hénot ${ }^{1}$, Vincent Langlois ${ }^{2}$, Nicolas Plihon ${ }^{1}$, and Nicolas Taberlet ${ }^{1}$ \\ ${ }^{1}$ Univ Lyon, Ens de Lyon, Univ Claude Bernard, CNRS, Laboratoire de Physique, F-69342 Lyon, France \\ ${ }^{2}$ Laboratoire de Géologie de Lyon, Terre, Planètes, Environnement, Université Claude Bernard Lyon 1 - ENS de Lyon - \\ Université Jean Monnet Saint-Étienne - CNRS, France
}

Correspondence: Nicolas Taberlet $<$ nicolas.taberlet@ens-lyon.fr $>$

\begin{abstract}
.
Glacier tables are structures frequently encountered on temperate glaciers. They consist of a rock supported by a narrow ice foot which forms through differential melting of the ice. In this article, we investigate their formation by following their dynamics on the Mer de glace glacier (Alps, France). We report field measurements of four specific glacier tables over the 5 course of several days, as well as snapshot measurements of a field of 80 tables performed on one given day. We develop a simple analytical 1-D heat conduction model accounting for the various mechanisms of the heat transfer on the glacier using local meteoreorological data, and which displays excellent agreement with the field measurements. We show that the formation of glacier tables results from a competition between two effects: on the one hand, a geometrical amplification of the heat flux received by the rock and transmitted to the ice underneath on the one hand, and on the other hand, a shielding effect resulting from the warmer temperature of the rocks compared to that of the ice (reducing the sensible and net infrared incident fluxes). The latter is greatly amplified by direct solar irradiation, which induces a strong temperature gradient across the thickness of the rock.
\end{abstract}

\section{Introduction}

A wide variety of spectacular shapes and patterns formed through differential ablation can be found in Nature: surface patterns known as rillenkarren result from the dissolution of soluble rocks (Cohen et al., 2016; Claudin et al., 2017; Cohen et al., 2020; Guérin et al., 2020), mushroom rocks undergo erosion of their base by strong particle-laden winds (Mashaal et al., 2020), and hoodoos which consist of a hard stone protecting a narrow column of sedimentary rock from rain-induced erosion (Young and Young, 1992; Bruthans et al., 2014; Turkington and Paradise, 2005).

On ice and snow surfaces, similar structures can be found: slender snow blades known as penitentes are caused by sublimation (Mangold, 2011; Bergeron et al., 2006; Claudin et al., 2015), suncusps consists of bowl-shaped depressions at the surface of a snow patch (Rhodes et al., 1987; Betterton, 2001; Mitchell and Tiedje, 2010), scallops which are regularly spaced patterns of surface indentations at the ice-water or ice-air interface (Bushuk et al., 2019), Zen stones found on frozen lakes are pebbles resting on a delicate ice pedestal protected from sun-induced sublimation (Taberlet and Plihon, 2021) and glacier tables (see fig. 1c) for which a foot of ice resists melting due mostly to thermal insulation provided by a large rock (Agassiz, 1840; Bouillette, 1933, 1934; Smiraglia and Diolaiuti, 2011; Hénot et al., 2021). 


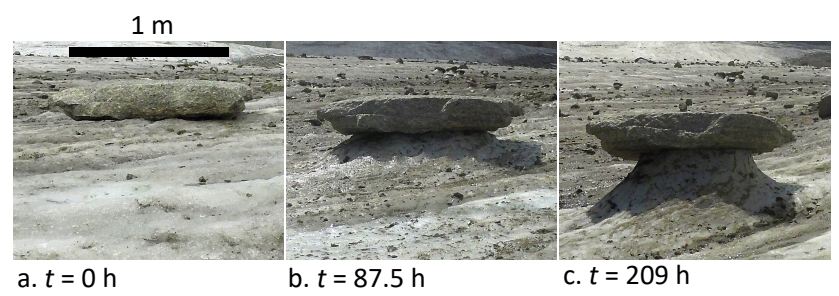

Figure 1. (a, b, c) Formation of a natural granite glacier table (rock 1, see Table 1).

On a temperate glacier, the ice ablation rate is influenced by the presence of debris on its surface. Indeed, a dense debris layer covering an ice surface can, when thin enough (less than $0.5 \mathrm{~cm}$ ), enhance the ice melting compared to a bare ice surface or, if thick enough, act as an insulation layer and reduce the melting rate (Östrem, 1959). The insulation effect is well-captured by complex energy balance models which use meteorological data as input parameters (Reid and Brock, 2010; Collier et al., 2014), and more recently using enhanced temperature index models (Carenzo et al., 2016; Moeller et al., 2016). The melt amplification effect for thin debris layers was explained by its patchiness (Reid and Brock, 2010) or by its porosity to air flow (Evatt et al., 2015). At a more local scale, patches of dirt or ashes on a glacier are known to lead to the formation of ice structures known as dirt cones, which consists of an ice cone covered with a centimetric layer of dirt (Swithinbank, 1950; Krenek, 1958; Drewry, 1972; Betterton, 2001).

Glacier tables (see fig. 1c) are structures frequently encountered on the leveled part of temperate glaciers (Agassiz, 1840). They typically consist of a meter-size rock supported by a column (or foot) of ice. They form over the course of a few days to a few weeks at the end of the spring, from May to June and may progressively disappear during the summer. Very large tables however, whose size can reach $10 \mathrm{~m}$, can last for several years (Bouillette, 1933, 1934). Glacier tables form because the ablation rate of the ice is lower under the rock than at the air-ice interface. When the ice foot becomes too thin, the table falls, usually on its south side. The ice foot progressively disappears and the rock can potentially form another table, if not too late in the season. Similarly to what is know for debris layers, smaller rocks tend not to form tables but can instead increase the melting rate and gradually sink into the ice, creating narrow and deep a hole which can reach up to $15 \mathrm{~cm}$ in depth (McIntyre, 1984). In a previous work (Hénot et al., 2021), artificial glacier tables were reproduced experimentally in a lab controlled environment (constant temperature, humidity, absence of wind), at a centimetric scale. The study focused on the initial behavior of pattern formation using cylindrical "rocks" of various sizes, aspect ratio and materials, initially resting on a flat ice surface. Although this small scale study under controlled conditions allowed one to understand the physical mechanisms that could play a role glacier table formation, it did not encompass the complexity of the energy balance on a natural glacier, in particular the effects of the direct solar irradiation and of the wind.

In this article, we report field observations made on the Mer de glace glacier (French Alps), of the formation dynamics of glacier tables monitored over the course of a few days, as well as a systematic measurement of already-formed tables on a given day. The Mer de Glace is a temperate glacier, meaning that the ice temperature is always given by the melting temperature of water, $T_{\text {ice }}=273 \mathrm{~K}$. We use local meteorological data to fit the ice ablation rate and characterize the heat transfer mechanisms 

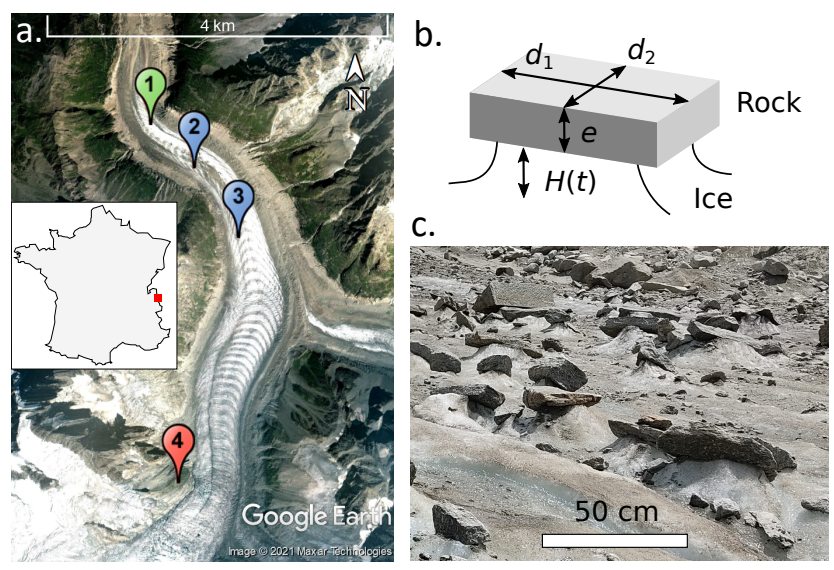

Figure 2. (a) Map of the Mer de Glace glacier in the French Alps (Google Earth Image ( 2021 Maxar Technologies) locating the measurement site of June $3^{\text {rd }} 2021$ (1), the timelapse observation sites of June 2021 (2) and June 2019 (3) and the Requin AWS (4). (b) 3D schematics of a typical glacier table defining the height $H(t)$ of the ice foot and the average thickness $e$ and widths $d_{1}$ and $d_{2}$ of the rock. (c) Picture of a portion of the glacier taken in June 2021 showing natural glacier tables, from which the data shown in fig. 3 were obtained.

at the surface of the glacier. We then develop a 1D conduction model taking into account the effect of the solar irradiation as well as sensible and longwave heat fluxes, which is in excellent agreement with the field measurements and which illustrates the synergistic effect between solar irradiation and sensible flux responsible for glacier table formation.

\section{Field measurements}

\subsection{Location and definitions}

In this article, we report two sets of observations made on the Mer de glace glacier: a time-resolved camera recording of the formation and evolution of four glacier tables and a field observation of 80 glacier tables.

The lower part of the Mer de Glace (below a $2000 \mathrm{~m}$ altitude) is largely covered with granitic debris, with sizes ranging from submillimetric up to several meters. In the following, their dimensions are characterized by their thickness $e$ and their larger and smaller widths $d_{1}$ and $d_{2}$ (see fig. 2b). We define an effective width of the rock $d_{\text {eff }}=2 d_{1} d_{2} /\left(d_{1}+d_{2}\right)$ whose expression will be justified in part 3.2 and the aspect ratio $\beta=e / d_{\text {eff }}$. The vertical distance from the bottom of a rock to the surface of the ice far from it is noted $H$. This quantity is either positive if the rock forms a table, in which case it corresponds to the height of the ice foot, or negative if the rock sinks into the ice surface, in which case it correspond to the depth of the hole. The thermal conductivity of granite was measured in a previous work (Hénot et al., 2021) as $\lambda=2.8 \mathrm{~W} \cdot \mathrm{m}^{-1} \cdot \mathrm{K}^{-1}$, which is in agreement with the literature (Cho et al., 2009). 


\subsection{Time evolution of four large tables}

Time-lapse images were obtained using an autonomous solar powered camera (Enlaps Tikee) placed on three $1.5 \mathrm{~m}$-long wood rods set into the ice. Pictures ( $4608 \mathrm{px} \times 3456 \mathrm{px}$ ) were taken every 30 min between 5 am and $10 \mathrm{pm}$ during 5 to 7 days until the camera fell on the ice due to the melting around the supporting rods. The movements of the device were corrected by tracking two fixed points on the background of the images. The positions of the top of the rocks were then manually pointed on each image. The formation of glacier tables created by four granite rocks of various shapes and dimensions was recorded in two time periods: A (7-14 June 2019) and B (4-9 June 2021) as summarized in table 1. Rocks 1, 2 and 4 were moved on clean flat ice, in front of the camera, the day before the recording started in order to provide a controlled initial state in which the rocks are lying on a horizontal ice surface ( $H=0$, see fig. 1a). Rock 3 was already standing on an ice foot, approximately $1 \mathrm{~m}$ high, at the beginning of period B (see suppl mat.). The evolution of the vertical position of these rocks is plotted in fig. 4a and e. The position of the ice surface was followed using a scaling rod, embedded into the ice and located approximately $2 \mathrm{~m}$ away from the rocks.

The surface temperature of rock 4 was measured every 5 min during period B using thermocouples and a homemade battery powered device (Arduino MKR ZERO and EVAL-CN0391-ARDZ Shield). The wind speed $u_{\mathrm{a}}$, air temperature $T_{\text {air }}$ and solar radiative flux $\Phi$ were measured at the Requin automatic weather station (AWS) (Nadeau et al., 2009) (located at $45^{\circ} 88^{\prime} \mathrm{N}$, $06^{\circ} 93^{\prime} \mathrm{E}$, see marker 4 on fig. 2a), $600 \mathrm{~m}$ higher and $3 \mathrm{~km}$ away from the measurement site. On a 2-week time period in July 2021, we also measured the air temperature at location 2, $3 \mathrm{~m}$ above the glacier surface (see suppl. mat.) which was systematically $2.5^{\circ} \mathrm{C}$ higher than the AWS data. In the rest of the article, we use the AWS data to which an offset was added: $T_{\text {air }}=T_{\text {air AWS }}+2.5^{\circ} \mathrm{C}$. We do not expect the measured solar flux and the wind speed to be significantly affected by the distance from the measurement site. The meteorological data are displayed in fig. $4 \mathrm{~b}-\mathrm{d}$ and f-h.

\subsection{An 800- $\mathrm{m}^{2}$ field comprising 80 glacier tables}

On June $3^{\text {rd }} 2021$, we systematically measured, in an area of $10 \mathrm{~m} \times 80 \mathrm{~m}$ located at point 1 in fig. $2 \mathrm{a}$, the dimensions of granite rocks (thickness and widths) as well as either the height of the ice foot supporting them $(H>0)$ or the depth of penetration in the ice $(H<0)$. The data of $H$ is plotted in fig. 3 as a function of the thickness $e$ and the widths $d_{1}$ and $d_{2}$ of the rocks. A detailed analysis and a modeling of these observations is provided below, but a first observation shows that there exists a critical size above which rocks tend to form glacier tables. The larger the rock, the greater its ability to protect the ice underneath from melting and, assuming all tables started their formation at the same time, the higher the ice foot. Below this critical size, however, the rocks have a tendency to sink into the ice surface. The transition between this two regimes seems sharper when considering the width of the rocks $\left(d_{\text {eff,crit }} \approx 0.2-0.3 \mathrm{~m}\right)$, instead of their thickness $\left(e_{\text {eff,crit }} \approx 0.02-0.1 \mathrm{~m}\right)$. This is reminiscent of the results obtained in a controlled environment in the absence of solar radiation, for which the transition occurred for a critical diameter $d_{\text {crit }, \tilde{\Phi}=0}=4 \lambda /\left(\eta h_{\text {eff }}\right)$ of the cylinders, independently of their aspect ratio (Hénot et al., 2021). 
https://doi.org/10.5194/tc-2021-299

Preprint. Discussion started: 11 October 2021

(c) Author(s) 2021. CC BY 4.0 License.

(c) (i)

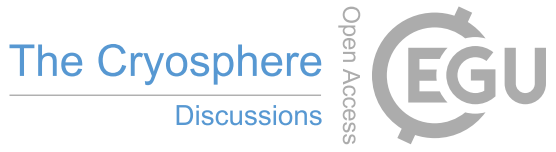

Table 1. Characteristics of the rocks studied.

\begin{tabular}{cccccc}
\hline $\begin{array}{l}\text { Rock } \\
\text { index }\end{array}$ & Loc. & $\begin{array}{c}\text { Period of } \\
\text { observation }\end{array}$ & $e(\mathrm{~m})$ & $d_{1} / d_{2}(\mathrm{~m})$ & $\beta$ \\
\hline \hline 1 & 3 & A: & 0.25 & $1.21 / 0.98$ & 0.23 \\
2 & & 7-14 Jun. 19 & 0.12 & $0.41 / 0.35$ & 0.32 \\
\hline 3 & 2 & B: & 1.7 & $3.5 / 3.5$ & 0.49 \\
4 & & 4-9 Jun. 21 & 0.095 & $0.32 / 0.31$ & 0.30 \\
\hline
\end{tabular}

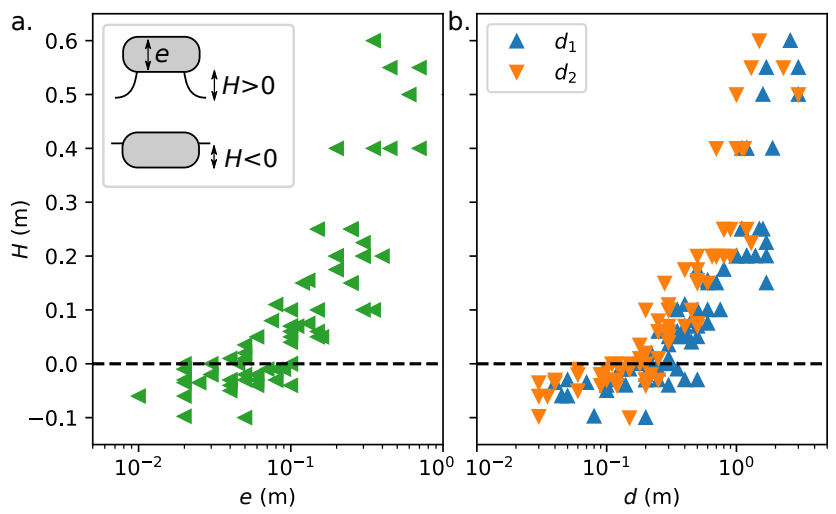

Figure 3. Raw data of the observation made at location 1 (see fig. 2a) on June $3^{\text {rd }} 2021$ : height of the ice foot $(H>0)$ or of the penetration depth of the rock in the ice $(H<0)$ as a function of the rock thickness $e$ (a) and widths $d_{1}$ and $d_{2}$ (b).

\section{Analysis and discussion}

\subsection{Ice melting}

The lowering of the ice surface of the glacier, due to melting, is shown with blue markers in fig. 4a and e. The daily ablation rate on clear-sky days was of the order of $8 \mathrm{~cm} \cdot$ day $^{-1}$ on period A ( $3 / 8$ clear-sky days) and $5.5 \mathrm{~cm} \cdot$ day $^{-1}$ on period B $(5 / 5 \mathrm{clear}$-sky days). In the following, we characterize the heat flux balance on the glacier surface by linking the ablated ice thickness to local meteorological data. The net incident heat flux causing the glacier surface to melt can, in general, be expressed as:

$Q_{\text {ice }}=Q_{\mathrm{SW}}+Q_{\mathrm{LW}}+Q_{\mathrm{H}}+Q_{\mathrm{L}}+Q_{\mathrm{R}}$

where $Q_{\mathrm{SW}}$ and $Q_{\mathrm{LW}}$ are the net shortwave and longwave radiative fluxes, $Q_{\mathrm{H}}$ and $Q_{\mathrm{L}}$ are the turbulent heat fluxes corresponding respectively to sensible and latent heat and $Q_{\mathrm{R}}$ is the flux associated with rain. In the following, we make simplification assumptions in order to extract the main physical mechanisms of the heat transfer on the glacier. The shortwave radiation (when neglecting the diffuse radiation) is given by $Q_{\mathrm{SW}}=\Phi\left(1-\alpha_{\text {ice }}\right.$ ), where $\alpha_{\text {ice }}$ is the ice albedo and $\Phi$ is the incoming direct solar radiative flux. The net longwave flux comes from a balance between the radiation emitted by the ice, at temperature $T_{\text {ice, }}$, and received from the atmosphere, at temperature $T_{\text {air }}$, (both emissivities are taken equal to 1) leading to 


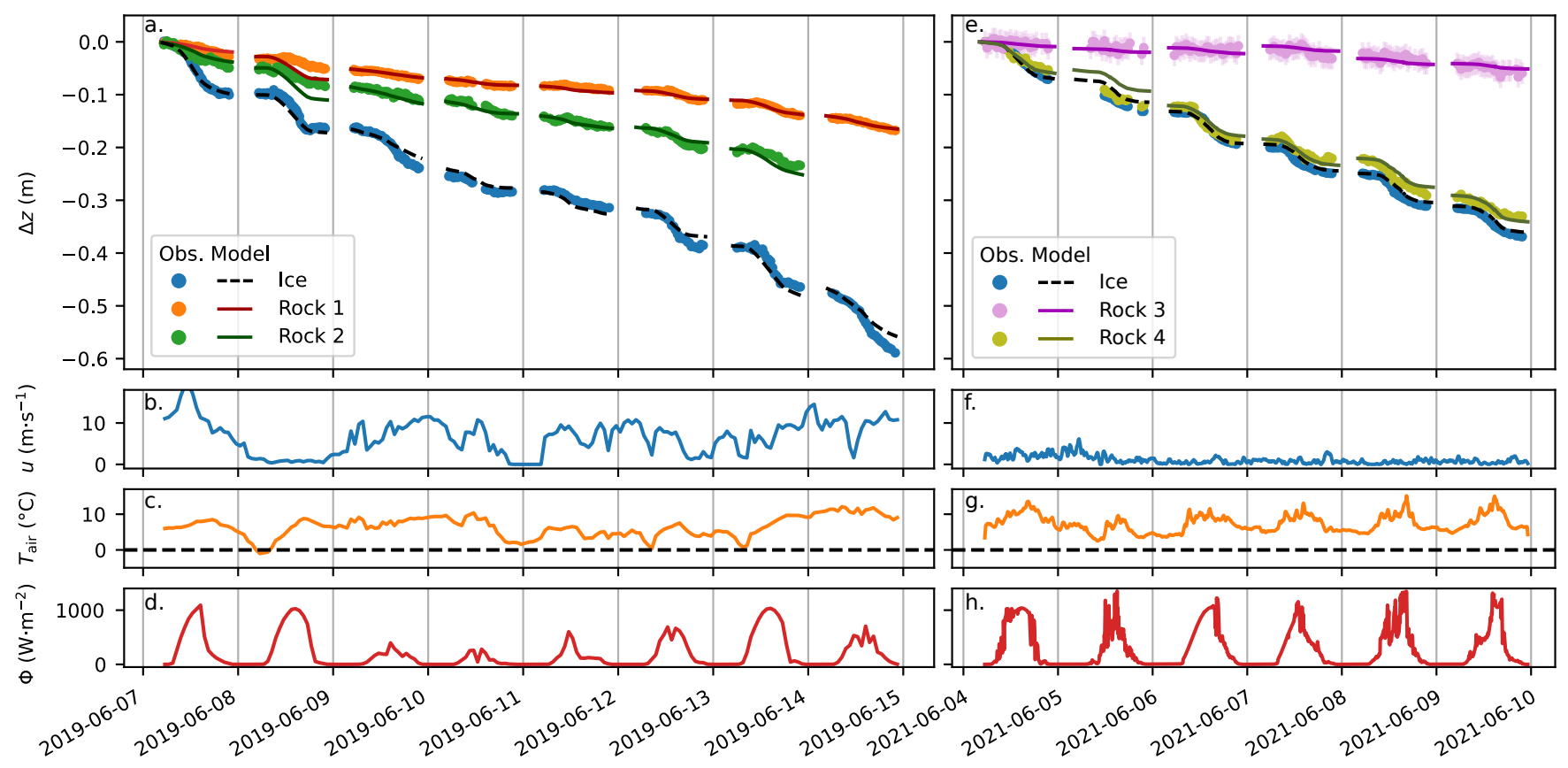

Figure 4. (a, e) Vertical position of the ice surface (blue markers), and of rocks 1 to 4 (colored markers, see table 1). The black dashed line corresponds to the model for ice ablation given by eq. 2 . The colored solid lines correspond to the model for rock given by eq. 7 . These models use as input meteorological data measured at the Requin AWS: wind speed $u_{\mathrm{a}}(\mathrm{b}, \mathrm{f})$, air temperature $T_{\text {air }}(\mathrm{c}, \mathrm{g})$ and solar radiation $\Phi$ $(\mathrm{d}, \mathrm{h})$.

$Q_{\mathrm{LW}}=\mathcal{F} \sigma\left(T_{\text {air }}^{4}-T_{\text {ice }}^{4}\right)$, where $\sigma$ is the Stefan-Boltzmann constant and $\mathcal{F}=0.7$ is a cloud factor whose value corresponds to clear sky conditions (Hock, 2005). As it will prove useful in the glacier table formation model, we linearize this expression around $T_{\text {ice }}: Q_{\mathrm{LW}} \approx 4 \mathcal{F} \sigma T_{\text {ice }}^{3}\left(T_{\text {air }}-T_{\text {ice }}\right)$ since $T_{\text {air }}-T_{\text {ice }} \ll T_{\text {ice }}$ (with temperatures in kelvins). The turbulent sensible flux is assumed to be proportional to the wind velocity: $Q_{\mathrm{H}}=\mathcal{C} u_{\mathrm{a}}\left(T_{\text {air }}-T_{\text {ice }}\right)$ where $\mathcal{C}$ is a constant depending on the surface rugosity (Brock et al., 2006; van der Veen, 2013). We neglect turbulent latent heat flux as it usually corresponds to less than $10 \%$ of the total flux (Hock, 2005). There were no precipitation and thus no associated heat flux on the glacier during the duration of our study. From this, the net total incident heat flux at the ice surface is:

$Q_{\text {ice }}=\Phi\left(1-\alpha_{\text {ice }}\right)+h_{\text {eff }}\left(T_{\text {air }}-T_{\text {ice }}\right)$

where $h_{\text {eff }}=4 \mathcal{F} \sigma T_{\text {ice }}^{3}+\mathcal{C} u_{\mathrm{a}}$ is an effective heat exchange coefficient accounting for sensible and longwave radiative fluxes. The incoming heat flux directly causes the ice to melt, and the vertical position of the ice surface is thus given by:

$z_{\text {ice }}(t)-z_{\text {ice }}(0)=-\mathcal{L}_{\text {fus }} \int_{0}^{t} Q_{\text {ice }}(t) \mathrm{d} t$

where $\mathcal{L}_{\text {fus }}=303 \mathrm{MJ} \cdot \mathrm{m}^{-3}$ is the volumetric enthalpy of fusion for ice. This model has two adjustable parameters: $\mathcal{C}$ and $\alpha_{\text {ice }}$. 
The black dashed lines in fig. $4 \mathrm{a}$ and e correspond to the application of eq. 2 and 3 using the values of the wind speed, air temperature and solar flux measured at the Requin AWS and displayed in fig. 4b-d and f-h, with parameters $\alpha_{\text {ice }}=0.33$ and $\mathcal{C}=2.3 \mathrm{~J} \cdot \mathrm{K}^{-1} \cdot \mathrm{m}^{-3}$ adjusted on the data of period A (see suppl. mat. for a discussion on the sensibility).

The agreement between our prediction and the field measurements is excellent, which validates the assumptions made. Note that the integration is reset every day from the last experimental value of the previous day in order to avoid the integration of a small error over several day. Moreover, the value of the adjusted ice albedo corresponds to what is reported in the literature for aged surface glacier ice (Brock et al., 2000; van der Veen, 2013). The value of the turbulent convection coefficient $\mathcal{C}$ also falls in the range (1.9 to $4.9 \mathrm{~J} \cdot \mathrm{K}^{-1} \cdot \mathrm{m}^{-3}$ ) previously reported (Nakawo and Young, 1981; Oerlemans and Klok, 2002). The effective heat exchange coefficient shows important variations between the two time periods going from $h_{\mathrm{eff}, \mathrm{A}}=18.2 \pm 8.4 \mathrm{~W} \cdot \mathrm{K}^{-1} \cdot \mathrm{m}^{-2}$ $($ mean $\pm \mathrm{SD})$ to $h_{\mathrm{eff}, \mathrm{B}}=5.6 \pm 1.9 \mathrm{~W} \cdot \mathrm{K}^{-1} \cdot \mathrm{m}^{-2}$. This is due to the drastic difference in mean wind speed, going from $6.5 \mathrm{~m} \cdot \mathrm{s}{ }^{-1}$ in period $\mathrm{A}$ to $1.0 \mathrm{~m} \cdot \mathrm{s}^{-1}$ in period $\mathrm{B}$, which in turn explains the variation in daily ablation rate between the two periods.

\subsection{Table formation}

Rocks 1 and 2 formed glacier tables over the course of approximately a week (see fig. 4a and e), after which they felt on their side. Rock 4 was initially sitting on an ice foot, which grew bigger, while rock 3 , although exhibiting dimensions close to those of rock 2 went down almost at the same rate than the bare ice surface and did not form any significant glacier table (see suppl. mat. for pictures).

In (Hénot et al., 2021), an analytical model was developed in order to explain the formation of artificial glacier tables made of cylindrical cap in a controlled environment, in which the heat transfer (natural convection of air and infrared radiation from the enclosure) was modelled through an effective heat exchange coefficient. In the following, we adapt this model to the non-symmetrical geometry of the rocks and we include the effect of solar irradiation and wind. Assuming that rocks are cuboids (see fig. 2b), the initial area of contact with the ice is $A_{\text {base }}=d_{1} d_{2}$ while the external area in contact with air is $A_{\text {ext }}=d_{1} d_{2}+2\left(d_{1}+d_{2}\right) e$. For the sake of simplicity this area will be considered constant, although it evidently varies over time. Yet, as discussed in Suppl. Mat., this has little effect on the heat transfer between the rock and the ice beneath.

The mean effective area on which the solar irradiation is received by a rock is denoted as $\left\langle A_{\text {sun }}\right\rangle$. This area should depend on the shape and orientation of the rock with respect to the course of the sun, but for sake of simplicity in the following it is simply assumed to be equal to the rock base surface area $\left\langle A_{\text {sun }}\right\rangle=d_{1} d_{2}$ (the validity of this assumption is discussed in the suppl. mat.). In a quasi-static regime, the energy balance of a rock can be written as:

$A_{\text {base }} Q_{\text {rock } \rightarrow \text { ice }}=A_{\text {ext }} h_{\text {eff }}\left(T_{\text {air }}-T_{\text {rock }}\right)+\left\langle A_{\text {sun }}\right\rangle\left(1-\alpha_{\text {rock }}\right) \Phi$

where $\alpha_{\text {rock }}=0.18$ is the albedo of the granite rock (measured by (Watson, 1971), see suppl. mat.) and $T_{\text {rock }}$ is the rock surface temperature, assumed homogeneous. Note that the heat flux received from the air and transmitted to the ice is amplified by a geometrical factor: $A_{\text {ext }} / A_{\text {base }}=1+2 e \frac{d_{1}+d_{2}}{d_{1} d_{2}}=1+4 e / d_{\text {eff }}=1+4 \beta$. The heat flux transmitted from the rock to the ice underneath can be estimated using a 1D conduction model as: $Q_{\text {rock } \rightarrow \text { ice }}=\lambda \frac{\left(T_{\text {rock }}-T_{\text {ice }}\right)}{d_{1 \mathrm{D}}}$ where $\lambda$ is the thermal conductivity of the rock and $d_{1 \mathrm{D}}$ is a length scale for the conduction process in the rock. It was postulated, and verified experimentally (see 


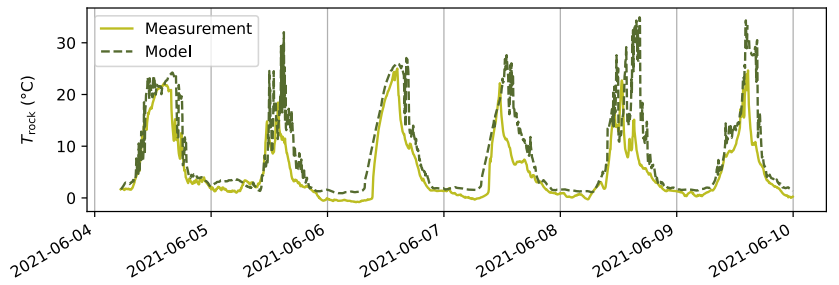

Figure 5. Temperature $T_{\text {rock }}$ of the top surface of rock 4 measured using a thermocouple (solid line) and computed using eq. 6 and the meteorological data of fig. 4f-h (dashed line).

fig. 5 of Hénot et al. (2021)), that this length could be estimated by:

$d_{1 \mathrm{D}}=\eta \frac{V_{\text {rock }}}{A_{\text {ext }}}=\eta \frac{e}{1+4 \beta}$

where $V_{\text {rock }}$ is the volume of the rock and $\eta=2.5$ is a numerical prefactor adjusted from the lab experiments. From this and eq. 4 , the temperature of the rock surface is:

$T_{\text {rock }}=T_{\text {ice }}+\frac{1}{1+\frac{\lambda}{h_{\text {eff } \eta e}}}\left[T_{\text {air }}-T_{\text {ice }}+\frac{\left(1-\alpha_{\text {rock }}\right) \Phi}{(1+4 \beta) h_{\text {eff }}}\right]$

and the heat flux transmitted to the ice can be expressed as:

$Q_{\text {rock } \rightarrow \text { ice }}=\frac{(1+4 \beta) h_{\text {eff }}\left(T_{\text {air }}-T_{\text {ice }}\right)+\left(1-\alpha_{\text {rock }}\right) \Phi}{1+\eta \frac{h_{\text {eff }}}{\lambda}}$

The integration of the flux given in eq. 7 is shown in solid lines in fig. $4 \mathrm{a}$ and e. The agreement between the measurements and the model prediction is over all very good for all four rocks, which validates the simple assumptions of the model. In our model under the quasi-static approximation, the heat flux received by the rock is assumed to be instantaneously transmitted to the ice underneath. Fig. 5 shows the measured temperature of the top surface of rock 4 (solid line) as well as the value predicted by eq. 6 using the meteorological data for $T_{\text {air }}, u_{\mathrm{a}}$ and $\Phi$.

As this seems to be well verified in the case of rock 4 whose temporal changes in surface temperature are well captured by the model, this is justified only if the rocks are not too thick compared to the thermal skin depth $\delta_{\text {diff }}=\sqrt{T_{\text {day }} D_{\text {rock }} / \pi}=0.2 \mathrm{~m}$ where $D_{\text {rock }}=1.4 \times 10^{-6} \mathrm{~m}^{2} \cdot \mathrm{s}^{-1}$ is the thermal diffusivity of the rock and $T_{\text {day }}=24 \mathrm{~h}$ is the period of variation of the external heat flux (i.e. $\Phi(t)$ ). This condition is indeed well verified for rock 4 , and acceptable for rocks 1 and 2 but not in the case of the $1.7 \mathrm{~m}$ thick rock 3 whose daily evolution of surface temperature can therefore not be captured by eq. 6 . However, due to the linearity of the heat exchange process with respect to the temperature, the daily average energy balance is expected to remain valid, which explains the good agreement between the data and the model for rock 3 in fig. $4 \mathrm{e}$.

Fig. 6a shows for each rock, the height of the ice foot, $H(t)=z_{\text {rock }}(t)-z_{\text {ice }}(t)$, as a function of the ablated ice thickness, $H_{\text {ice }}(t)=z_{\text {ice }}(t)-z_{\text {ice }}(0)$. On average these quantities appear to be proportional to each other. From the model developed previously, the daily average of the ratio $H / H_{\text {ice }}$ can be expressed as: $\left\langle H / H_{\text {ice }}\right\rangle=1-\left\langle Q_{\text {rock } \rightarrow \text { ice }} / Q_{\text {ice }}\right\rangle$. Using eq. 2 and 7 

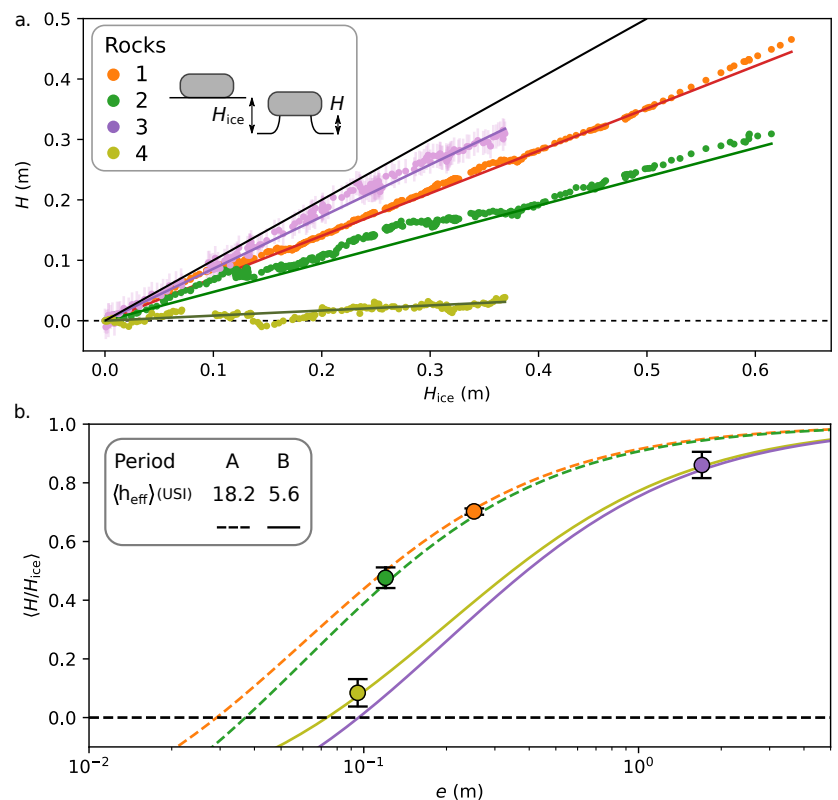

Figure 6. (a) Evolution of the height $H$ of the ice foot under rocks 1-4 as a function of the ice ablated thickness $H_{\text {ice }}$. The colored lines correspond to linear adjustments of the data. The black solid line has a slope 1. (b) Mean ratio of the height $H$ of the ice foot under a rock and of the total ablated ice thickness $H_{\text {ice }}$ since the beginning of the table formation, as a function of the thickness $e$ of the rock. The markers correspond to the slopes of fig. a for each rocks. The lines correspond to the model (eq. 8) for a typical mean solar flux $\left(\langle\Phi\rangle=340 \mathrm{~W} \cdot \mathrm{m}^{-2}\right)$, using the $\left\langle h_{\mathrm{eff}}\right\rangle$ values measured in period A (dashed lines) and B (solid lines) and the aspect ratio $\beta$ of each rock given in table 1 .

and using the average value for $T_{\text {air }}$ :

$\left\langle\frac{H}{H_{\text {ice }}}\right\rangle=1-\frac{1+4 \beta+\left(1-\alpha_{\text {rock }}\right)\langle\tilde{\Phi}\rangle}{1+\eta \frac{\left\langle h_{\text {eff }}\right\rangle}{\lambda} e} \frac{1}{1+\left(1-\alpha_{\text {ice }}\right)\langle\tilde{\Phi}\rangle}$

where $\langle\tilde{\Phi}\rangle=\langle\Phi\rangle /\left(h_{\text {eff }}\left(T_{\text {air }}-T_{\text {ice }}\right)\right)$ is a dimensionless number characterizing the effect of solar radiation. Note that this expression does not depend on the hourly meteorological data but rather on averaged values over the time period of interest. On both periods $\mathrm{A}$ and $\mathrm{B}, T_{\text {air }} \approx 7^{\circ} \mathrm{C}$ and $\langle\Phi\rangle \approx 340 \mathrm{~W} \cdot \mathrm{m}^{-1}$ on clear-sky days.

Equation 8 predicts the linear behaviour of $H$ vs. $H_{\text {ice }}$ and allows one to compute their ratio, which evidently depends on the tickness of the rock, $e$, which is plotted in fig. $6 \mathrm{~b}$ for periods $\mathrm{A}$ (dashed lines) and $\mathrm{B}$ (solid lines) for each rock aspect ratio $\beta$. Here also the agreement between the field measurements and the model is excellent and illustrates the sensibility of the table formation dynamics to the effective heat exchange coefficient and thus to the mean wind speed.

\subsection{Analysis of the $\mathbf{8 0}$ glacier tables field}

Having successfully modelled the time evolution of the 4 larger glacier tables, the model can be applied to the data obtained on a given day for a field comprising 80 rocks. 

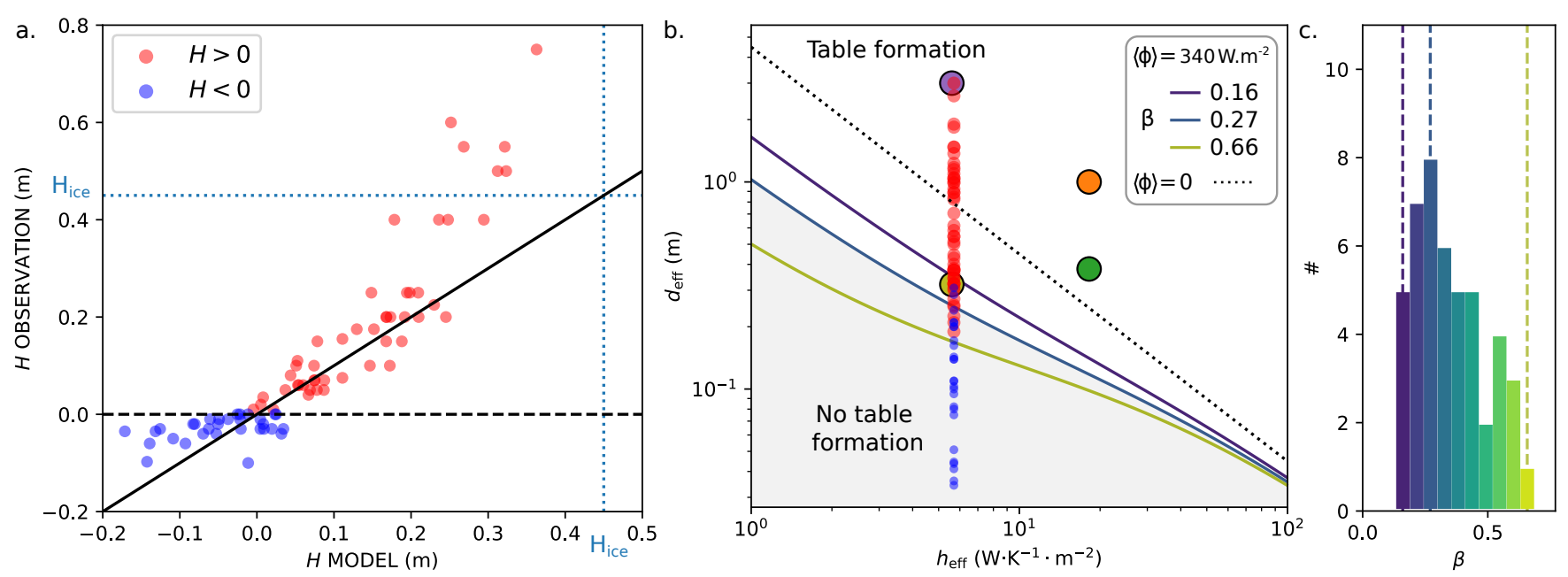

Figure 7. (a) Observation versus model for the distance $H$ between the bottom of rocks and the ice surface for the data measured on June $3^{\text {rd }} 2021$ (see fig. 3). The solid black line has a slope 1 and the dotted lines correspond to the ablated ice thickness $H_{\text {ice }}$ since the melting of the snow layer (see suppl. mat.). (b) Diagram of the ability for a rock to form a table as a function of its typical width $d_{\text {eff }}$ and the effective heat exchange coefficient $h_{\text {eff }}$ given by eq. 9 . The dotted line corresponds to the delimitation predicted by the model in the absence of solar irradiation $(\langle\tilde{\Phi}\rangle=0)$. The solid colored lines correspond to the case of typically measured solar radiation and different rock aspect ratio. The small circles correspond to the data of (a) and are represented in red if a table is observed $(H>0)$ and in blue otherwise. The larger circles correspond to rocks 1-4. (c) Distribution of the aspect ratio $\beta$ of the rocks close to the transition between the two regimes $(|H|<0.2 \mathrm{~m})$. The vertical dashed lines correspond to the limits plotted in fig. b.

The snow layer covering that part of the glacier finished melting on May 26, leaving the ice exposed. The meteorological data of the time period C (from May 26 until June 3), alongside with the previously adjusted parameters $\alpha_{\text {ice }}$ and $C$ allows to compute the thickness of ablated ice $H_{\text {ice }}=0.45 \pm 0.05 \mathrm{~m}$ during this period (see fig. S5 of the suppl. mat.). The mean air temperature during time period $\mathrm{C}$ was $T_{\text {air }} \approx 6^{\circ} \mathrm{C}$. The mean wind speed was $\left\langle u_{\mathrm{a}}\right\rangle=1.1 \mathrm{~m} \cdot \mathrm{s}^{-1}$ leading to an effective heat exchange coefficient of $h_{\mathrm{eff}, \mathrm{C}}=5.7 \pm 2.4 \mathrm{~W} \cdot \mathrm{K}^{-1} \cdot \mathrm{m}^{-2}$. Not taking into account the effect of direct solar irradiation, this coefficient would lead to a critical diameter $d_{\text {crit }, \tilde{\Phi}=0}=4 \lambda /\left(\eta h_{\text {eff }}\right)=2 \mathrm{~m}$, far larger than what is observed on fig. 3. The observed values of $H$ are plotted on fig. 7a as a function of the ones computed for each rock using eq. 8 which takes into account the effect of the sun. It shows an excellent agreement with no new adjustable parameters, between the observed and predicted values for $0<H<0.35 \mathrm{~m}$, meaning that these rocks started to form glacier tables at the beginning of period $\mathrm{C}$. The rocks standing on taller ice feet probably started to form glacier tables before May 26. They correspond to bigger rocks that may have emerge from the snow layer early on. As for the rocks that sunk into the ice surface $(H<0$, in blue markers), the expression of eq. 8 is not expected to remain valid after the onset of the formation as the geometrical amplification effect disappears if the rock is set into the ice. We can therefore conclude that using the previously determined values of $\alpha_{\text {ice }}$ and $C$ allows on to satisfyingly predict the height of glaciers tables above the critical diameter. 
That critical diameter corresponding to the transition between the two regimes (the rock sink into the ice or form a table), is set by $\left\langle H / H_{\text {ice }}\right\rangle=1$, and can be expressed as:

$d_{\text {crit }}=\frac{\lambda}{\eta \beta\left\langle h_{\text {eff }}\right\rangle} \frac{4 \beta+\left(\alpha_{\text {ice }}-\alpha_{\text {rock }}\right)\langle\tilde{\Phi}\rangle}{1+\left(1-\alpha_{\text {ice }}\right)\langle\tilde{\Phi}\rangle}$

Fig. $7 \mathrm{~b}$ shows a diagram of the ability for a rock to form a table as a function of its effective width $d_{\text {eff }}$ (which in practice can be replaced by the mean width) and the effective heat exchange coefficient $h_{\text {eff }}$ for various values of the rock aspect ratio. The four monitored rocks as well as the field data from the 80 rocks found in the $800-\mathrm{m}^{2}$ field are plotted in this diagram. The distribution of aspect ratio $\beta$ of rocks ( 46 of them) close to the transition (defined by $|H|<0.2 \mathrm{~m}$ ) is plotted in fig.7c. The bounding values $(\beta=0.16$ and 0.66$)$ as well as the value corresponding to the maximum of the distribution $(\beta=0.27)$ are used to plot in fig. $7 \mathrm{~b}$ the results of the model given by eq. 9 , which shows an excellent agreement with the transition visible in the field data. This diagram illustrates the sensibility of the table formation to the effective heat exchange coefficient: the critical size above which a rock can form a table differs by a factor 2 between the two periods A (windy) and B (no wind). The dotted line corresponds to the model prediction in the absence of solar radiation and shows that the sun has the effect of lowering the critical size despite the lower albedo of the rocks compared to the ice.

\subsection{Physical discussion}

The ability for a rock to form a table appears to be controlled by two opposing effects. On the one hand, the heat flux received by the rock from the environment on all its surface (sensible heat flux and longwave radiation) and transmitted to the ice is amplified by a geometrical factor related to the aspect ratio of the rock. This effect dominates for small rocks and can cause them to sink into the ice surface. The lower albedo of the rock compared to the ice also lead to an amplification of the direct solar radiation. On the other hand, there is an attenuation effect of a portion of the heat flux received by the ice under the rock compared to the one received far away from it. The heat flux that depends on the surface temperature of the body receiving it (sensible heat flux related to thermal convection and net longwave radiative flux) are smaller for rocks than for ice as they are warmer. This effect is controlled by a dimensionless parameter: $h_{\mathrm{eff}} e / \lambda$. The higher this number, the stronger the attenuation effect, which is thus dominant for large rocks. This effect was already identified and discussed in (Hénot et al., 2021). In natural conditions, this effect amplified by the solar irradiation which imposes a thermal flux going from the rock top surface to the ice and induces a temperature gradient inside the rock. This rises the surface temperature of the rock which amplifies the cooling effect due to the wind and the infrared emission. Overall, the effect or solar irradiation lowers by a factor 2 to 4 the critical size for which a rock is able to form a glacier table.

\section{Conclusions}

We studied the formation of four glacier tables over the course of a week and we measured the characteristics of 80 glacier tables on the Mer de Glace glacier (Alps). We found out that the size of the rocks is a determinant factor governing table formation: the bigger the rock, the higher and faster the ice foot supporting it will grow. Under a critical size, rocks show 
https://doi.org/10.5194/tc-2021-299

Preprint. Discussion started: 11 October 2021

(c) Author(s) 2021. CC BY 4.0 License.

(c) (i)

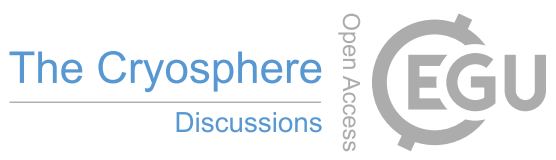

the opposite behaviour of sinking into the ice surface. We developed an analytical conduction model taking into account the infrared and solar radiation and sensible heat flux received by a rock and by the glacier ice surface using local meteorological data.

240 Author contributions. MH, VL, NP and NT conceived the study and performed the fieldwork. MH performed the data analysis, developed the model and drafted the manuscript. All authors contributed to the data interpretation, discussion of the results and writing of the manuscript.

Competing interests. The authors declare that they have no conflict of interest.

Acknowledgements. This study received financial support from the Fédération de Recherche André Marie Ampère and Laboratoire de Physique at ENS de Lyon. The authors acknowledge technical support and useful scientific discussion with Marine Vicet, Jérémy Vessaire 245 and Thierry Dauxois. 
https://doi.org/10.5194/tc-2021-299

Preprint. Discussion started: 11 October 2021

(c) Author(s) 2021. CC BY 4.0 License.

(c) (i)

\section{References}

Agassiz, L.: Études sur les glaciers, Gent \& Gassman, Neuchâtel, 1840.

Bergeron, V., Berger, C., and Betterton, M. D.: Controlled Irradiative Formation of Penitentes, Physical Review Letters, 96, https://doi.org/10.1103/physrevlett.96.098502, 2006.

Betterton, M. D.: Theory of structure formation in snowfields motivated by penitentes, suncups, and dirt cones, Phys. Rev. E, 63, 056129 , https://doi.org/10.1103/PhysRevE.63.056129, 2001.

Bouillette, E.: Une Superbe Table des Glaciers, L'Astronomie, 47, 201-202, 1933.

Bouillette, E.: La fin d'une table des glaciers, L'Astronomie, 48, 89-91, 1934.

Brock, B. W., Willis, I. C., and Sharp, M. J.: Measurement and parameterization of albedo variations at Haut Glacier d'Arolla, Switzerland, Journal of Glaciology, 46, 675-688, https://doi.org/doi:10.3189/172756500781832675, 2000.

Brock, B. W., Willis, I. C., and Sharp, M. J.: Measurement and parameterization of aerodynamic roughness length variations at Haut Glacier d'Arolla, Switzerland, Journal of Glaciology, 52, 281-297, https://doi.org/10.3189/172756506781828746, 2006.

Bruthans, J., Soukup, J., Vaculikova, J., Filippi, M., Schweigstillova, J., Mayo, A. L., Masin, D., Kletetschka, G., and Rihosek, J.: Sandstone landforms shaped by negative feedback between stress and erosion, Nature Geoscience, 7, 597-601, https://doi.org/10.1038/ngeo2209, 2014.

Bushuk, M., Holland, D. M., Stanton, T. P., Stern, A., and Gray, C.: Ice scallops: a laboratory investigation of the ice-water interface, Journal of Fluid Mechanics, 873, 942-976, https://doi.org/10.1017/jfm.2019.398, 2019.

Carenzo, M., Pellicciotti, F., Mabillard, J., Reid, T., and Brock, B. W.: An enhanced temperature index model for debris-covered glaciers accounting for thickness effect, Advances in Water Resources, 94, 457-469, https://doi.org/10.1016/j.advwatres.2016.05.001, 2016.

Cho, W., Kwon, S., and Choi, J.: The thermal conductivity for granite with various water contents, Engineering Geology, 107, 167 - 171, https://doi.org/https://doi.org/10.1016/j.enggeo.2009.05.012, 2009.

Claudin, P., Jarry, H., Vignoles, G., Plapp, M., and Andreotti, B.: Physical processes causing the formation of penitentes, Physical Review E, 92, https://doi.org/10.1103/physreve.92.033015, 2015.

Claudin, P., Durán, O., and Andreotti, B.: Dissolution instability and roughening transition, Journal of Fluid Mechanics, 832, https://doi.org/10.1017/jfm.2017.711, 2017.

Cohen, C., Berhanu, M., Derr, J., and du Pont, S. C.: Erosion patterns on dissolving and melting bodies, Physical Review Fluids, 1, 050 508, https://doi.org/10.1103/PhysRevFluids.1.050508, 2016.

Cohen, C., Berhanu, M., Derr, J., and Du Pont, S. C.: Buoyancy-driven dissolution of inclined blocks: Erosion rate and pattern formation, Physical Review Fluids, 5, 053 802, https://doi.org/10.1103/PhysRevFluids.5.053802, 2020.

Collier, E., Nicholson, L., Brock, B., Maussion, F., Essery, R., and Bush, A.: Representing moisture fluxes and phase changes in glacier debris cover using a reservoir approach, The Cryosphere, 8, 1429-1444, https://doi.org/10.5194/tc-8-1429-2014, 2014.

Drewry, D. J.: A Quantitative Assessment of Dirt-Cone Dynamics, Journal of Glaciology, 11, 431-446, https://doi.org/10.3189/S0022143000022383, 1972.

Evatt, G. W., Abrahams, I. D., Heil, M., Mayer, C., Kingslake, J., Mitchell, S. L., Fowler, A. C., and Clark, C. D.: Glacial melt under a porous debris layer, Journal of Glaciology, 61, 825-836, https://doi.org/10.3189/2015JoG14J235, number: 229, 2015.

Guérin, A., Derr, J., Du Pont, S. C., and Berhanu, M.: Streamwise dissolution patterns created by a flowing water film, Physical Review Letters, 125, 194 502, https://doi.org/10.1103/PhysRevLett.125.194502, 2020. 
https://doi.org/10.5194/tc-2021-299

Preprint. Discussion started: 11 October 2021

(c) Author(s) 2021. CC BY 4.0 License.

(c) (i)

Hénot, M., Plihon, N., and Taberlet, N.: Onset of Glacier Tables, Phys. Rev. Lett., 127, 108501, https://doi.org/10.1103/PhysRevLett.127.108501, 2021.

Hock, R.: Glacier melt: a review of processes and their modelling, Progress in Physical Geography: Earth and Environment, 29, 362-391, https://doi.org/10.1191/0309133305pp453ra, number: 3, 2005.

Krenek, L. O.: The Formation of Dirt Cones on Mount Ruapehu, New Zealand, Journal of Glaciology, 3, 312-315, https://doi.org/10.3189/S0022143000023984, 1958.

Mangold, N.: Ice sublimation as a geomorphic process: A planetary perspective, Geomorphology, 126, 1-17, https://doi.org/10.1016/j.geomorph.2010.11.009, 2011.

Mashaal, N. M., Sallam, E. S., and Khater, T. M.: Mushroom rock, inselberg, and butte desert landforms (Gebel Qatrani, Egypt): evidence of wind erosion, International Journal of Earth Sciences, 109, 1975-1976, https://doi.org/10.1007/s00531-020-01883-z, 2020.

McIntyre, N. F.: Cryoconite hole thermodynamics, Canadian Journal of Earth Sciences, 21, 152-156, https://doi.org/10.1139/e84-016, 1984.

Mitchell, K. A. and Tiedje, T.: Growth and fluctuations of suncups on alpine snowpacks, Journal of Geophysical Research, 115, https://doi.org/10.1029/2010JF001724, number: F4, 2010.

Moeller, R., Moeller, M., Kukla, P. A., and Schneider, C.: Impact of supraglacial deposits of tephra from Grímsvötn volcano, Iceland, on glacier ablation, Journal of Glaciology, 62, 933-943, https://doi.org/10.1017/jog.2016.82, 2016.

Nadeau, D. F., Brutsaert, W., Parlange, M., Bou-Zeid, E., Barrenetxea, G., Couach, O., Boldi, M.-O., Selker, J. S., and Vetterli, M.: Estimation of urban sensible heat flux using a dense wireless network of observations, Environmental Fluid Mechanics, 9, 635-653, https://doi.org/10.1007/s10652-009-9150-7, 2009.

Nakawo, M. and Young, G.: Field experiments to determine the effect of a debris layer on ablation of glacier ice, Annals of Glaciology, 2, 85-91, https://doi.org/10.3189/172756481794352432, 1981.

Oerlemans, J. and Klok, E.: Energy balance of a glacier surface: analysis of automatic weather station data from the Morteratschgletscher, Switzerland, Arctic, Antarctic, and Alpine Research, 34, 477-485, https://doi.org/10.1080/15230430.2002.12003519, 2002.

Reid, T. D. and Brock, B. W.: An energy-balance model for debris-covered glaciers including heat conduction through the debris layer, Journal of Glaciology, 56, 903-916, https://doi.org/10.3189/002214310794457218, number: 199, 2010.

Rhodes, J. J., Armstrong, R. L., and Warren, S. G.: Mode of Formation of "Ablation Hollows" Controlled by Dirt Content of Snow, Journal of Glaciology, 33, 135-139, https://doi.org/10.3189/S0022143000008601, 1987.

Smiraglia, C. and Diolaiuti, G.: Encyclopedia of Snow, Ice and Glaciers, chap. Epiglacial Morphology, pp. 262-267, Springer, 2011.

310 Swithinbank, C.: The origin of dirt cones on glaciers, Journal of Glaciology, 1, 461-465, https://doi.org/10.3189/S0022143000012880, 1950.

Taberlet, N. and Plihon, N.: Sublimation-driven morphogenesis of Zen stones on ice surfaces, Proceedings of the National Academy of Sciences, 118, https://doi.org/10.1073/pnas.2109107118, 2021.

Turkington, A. V. and Paradise, T. R.: Sandstone weathering: a century of research and innovation, Geomorphology, 67, 229-253, https://doi.org/10.1016/j.geomorph.2004.09.028, 2005.

315 van der Veen, C. J.: Fundamentals of Glacier Dynamics, CRC Press, 2013.

Watson, R. D.: Spectral reflectance and photometric properties of selected rocks, Remote Sensing of Environment, 2, 95-100, https://doi.org/https://doi.org/10.1016/0034-4257(71)90082-4, 1971.

Young, R. and Young, A.: Sandstone Landforms, Lecture Notes in Physics, Springer-Verlag, https://books.google.fr/books?id= Da8rvwEACAAJ, 1992. 
https://doi.org/10.5194/tc-2021-299

Preprint. Discussion started: 11 October 2021

(C) Author(s) 2021. CC BY 4.0 License.

(c) (i)

320 Östrem, G.: Ice Melting under a Thin Layer of Moraine, and the Existence of Ice Cores in Moraine Ridges, Geografiska Annaler, 41, 228-230, http://www.jstor.org/stable/4626805, 1959. 